\title{
AC 2009-1762: WATER ANALYSIS, TRAINING, EDUCATION, AND RESEARCH SERVICES: A "FARMER'S COOPERATIVE" MODEL FOR CAPACITY DEVELOPMENT
}

\section{Jana Fattic, Western Kentucky University}

Jana Fattic is the Associate Director of the Center for Water Resource Studies and Operations Director of the WATERS Laboratory at Western Kentucky University. Ms. Fattic's role as Associate Director of the Center includes budget development and project coordination of state and federal grants totaling over one million dollars annually. Ms. Fattic's responsibilities include day-to day administration, budget and personnel management, quality assurance and quality control, and maintenance of certifications. She holds a Bachelor of Science degree from Western Kentucky University, and has worked in both the public sector as a regulator and private sector as an environmental consultant prior to being employed by the Center.

\section{Andrew Ernest, Western Kentucky University}

Dr. Ernest earned a B.S. and M.S. in Civil Engineering from the University of Southwestern Louisiana in 1985 and in 1986 respectively, and a Ph.D. in Civil Engineering from Texas A\&M University in 1991. He has over 16 years of professional experience in Environmental and Water Resource engineering, having managed a variety of organizational units with varying missions, encompassing consulting, academic, revenue-driven, research and service activities. Dr. Ernest currently serves as the Director of the Center for Water Resource Studies and the Associate Dean of the Ogden College of Science and Engineering at Western Kentucky University, is a Principal Engineer with Ernest and Sons Civil and Environmental Engineering consultants and a proponent of the principles of Open Engineering. He serves on Kentucky's Environmental Quality Commission, the Kentucky Board of Certification for Wastewater System Operators and a variety of other local, state and regional committees. He is a licensed engineer in Kentucky and Texas, and is a Board Certified Environmental Engineer through the American Academy of Environmental Engineers, with specialty certification in Water and Wastewater. 


\title{
Water Analysis, Training, Education and Research Services: A 'Farmer's Cooperative' Model for Capacity Development
}

\begin{abstract}
Upon its inception, WATERS Laboratory in Bowling Green, Kentucky was envisioned as a 'farmer's cooperative' of labs. This consortium of local, state and regional private and public sector entities maximizes each partner's ability to further their goals through resource sharing.

The foundation of the lab was established in 2004 when Western Kentucky University (WKU) and Mammoth Cave National Park (MACA) of the National Park Service (NPS) entered into a Cooperative Agreement to share laboratory analytical equipment and personnel to maximize utility, productivity and scope of service. The Cooperative Agreement has resulted in the establishment of an operating environment that integrates and furthers the research, training and service components of the partners in the area of overlap pertinent to the natural resource protection mission of the NPS and the training and educational mission of WKU. This facility consolidates the research and regulatory grade environmental analytical instrumentation available to each partner and has resulted in optimal utilization of resources.
\end{abstract}

This partnership permits programs to attain and exceed institutional goals for data collection, determination, analysis and visualization through coordinated collaboration and access to services traditionally beyond the resource capacities of each individual organization. This paper will explore the first five years of operation of this entity, its contribution to environmental engineering education, training and capacity development.

\section{Background}

Western Kentucky University (WKU) established the Office of Research and Economic Development in 2005, along with a new Associate Vice President for Research and Economic Development reporting to the University Provost. In addition to consolidating most research and graduate program units under one roof, including the Office of Sponsored Programs, and College of Graduate Studies, the new Office established an office for technology licensing and the WKU Center for Research and Development (The Center). The Center, is co-located with the Central Region Innovation and Commercialization Center (ICC), a regional technology accelerator funded by the Commonwealth of Kentucky and local governments. The Applied Research and Technology Program (ARTP) is a Program of Distinction within the Ogden College of Science and Engineering at WKU, emphasizing the integration of undergraduate research, technology development and transfer, and stimulation of entrepreneurship as a mechanism for technologybased regional economic development. The ARTP seeds and facilitates the establishment and growth of multi-disciplinary centers supporting its integrative mission. Several ARTP centers that epitomize the public-private sector vision are located adjacent to the ICC and The Center, providing a catalyst and attractor for technology startups.

The Center for Water Resource Studies (CWRS) is an ARTP Center specializing in the transfer of cutting-edge research into practical water resource management tools. The Center maintains a 
full staff of qualified technical professionals providing a broad range of services, including: Water and Wastewater Laboratory Analysis; DNA Cloning and Sequencing; Operational Troubleshooting; Specialized Training; Mapping and Modeling; Sampling and Monitoring; Applications Development; Proof-of-Concept and Technology Verification. Center staff act at the interface between university research faculty and graduate and undergraduate students to provide effective translation of ideas into action. The CWRS is organized into three divisions The Water Analysis, Training, Education and Research Services laboratory consortium; the Environmental Informatics and Information Technology division; and the Field Operations and Outreach division. The Water Analysis, Training, Education and Research Services (WATERS) Laboratory is a State certified laboratory specializing in the analysis of drinking water, wastewater and source water for compliance with State and Federal regulations. WATERS provides cost-effective analytical services to water and wastewater treatment facilities, industries, and the general public by using state-of-the-art instruments and experienced staff. The Field Operations and Outreach Division (FOO) is staffed by trained and certified professionals specializing in the collection of field data and on-site training and technical support. This unit provides sub-foot GPS mapping, sample collection, monitoring program development and implementation services under rigorous quality control standards. The division provides mapping and data collection services to municipalities and utilities, in-stream water quality monitoring campaigns for watershed planning and Total Maximum Daily Load development, and water, wastewater and stormwater system evaluations. The Environmental Informatics and Information Technology Division (EIIT) employs state-of-the-art Geographic Information System (GIS) technologies and software development environments in the design and development of analysis and visualization applications. The integrated Information Technology (IT) and environmental expertise allows the division to develop real-world applications that meet both the IT demands and the requirements of the water districts within our region. The Division specializes in the integration of web and GIS applications and mapping tools, rules based logic, expert systems and semantic web applications.

\section{Mission}

WATERS espouses the following integrated mission components through cooperation between partners:

- Research: Maximizing the ability of each partnering agency's ability to further their research missions through the optimal utilization of research and regulatory grade instrumentation through the formalization of resource sharing.

- Training: Provision of formal training and certification of field, laboratory and environmental technicians serving an immediate need for the Commonwealth of Kentucky.

- $\quad$ Service: Enabling local, state and regional private and public sector entities to meet environmental management goals through the provision of high quality environmental data collection, management and analysis.

\section{Goals}


WATERS achieves its mission through the following goals:

- Water Analysis: Drinking water bacteriological samples for small water systems; Reservoir Monitoring Study.

- Training: Provision of formal training and certification of field, laboratory and environmental technicians serving an immediate need for the Commonwealth of Kentucky.

- Education: Student certification program, hands-on work experience for undergraduate students in the environmental science field.

- Research: Maximizing the ability of each partnering agency's ability to further their research missions by the optimal utilization of research-grade instrumentation through the formalization of resource sharing.

- Service: Enabling local, state and regional private and public sector entities to meet environmental management goals through the provision of high quality environmental data collection, management and analysis.

\section{History}

The Ogden Environmental Laboratory (OEL) was established in 1990 as a revenue-dependent unit at WKU to support the compliance monitoring requirements of the Safe Drinking Water Act. The mission of the OEL was to provide cost effective analytical services to the small community water systems being established to serve the rural populations of the Commonwealth. The goal was to provide state certified analytical services, while engaging students as much as possible in the day-to-day activities of the facility. While revenue production was not a primary concern, the OEL was expected to develop and maintain a sufficient client base to ensure solvency. Over the subsequent years, the OEL expanded its scope of services to include state certified wastewater analyses and physico-chemical and microbiological analyses for in-stream water quality determination.

By 2003, the OEL suite of services, infrastructure and client base had peaked and was experiencing a steady decline, to the point of being financially insolvent for several years. A detailed performance assessment was conducted on the OEL, determining that the suite of commercially valued services, i.e state certified analyses, had gradually eroded. At the time of the assessment, the lab was only certified to conduct one type of analysis, which at that time constituted the bulk of its source of revenue. A review of operational and management practices revealed a consistent lack of adequate investment in equipment maintenance, resulting in most major pieces of instrumentation gradually being decommissioned and not replaced. All analytical services, both certified and not, reliant on that equipment were then discontinued, often resulting in a broader loss of revenue as clients moved their entire orders to other providers.

Within the same timeframe, a workload assessment conducted on the Water Quality Laboratory at the Mammoth Cave National Park (MACA) revealed a well equipped and instrumented 
facility staffed with two technicians. However, the staffing levels were insufficient to keep up with the volume of samples needing to be processed, while instruments utilization rates were low.

The condition of the OEL and the staffing needs of the MACA facility prompted the development of a cooperative strategy to address both situations in a mutually beneficial manner. In essence, MACA and WKU entered into a Memorandum of Agreement (MoA) creating the WATERS, in which WKU agreed to house the operation as well as act as its fiscal agent. MACA agreed to delegate its staff and laboratory equipment for use by the new lab. Several logistical details had to be addressed in the process. The most significant of which was the mechanism by which National Park Service employees delegated to WATERS could enjoy effective staff status and both supervise and be supervised by WKU employees. A core precept adhered to during the inception of the WATERS lab, was a goal to expand membership beyond the two initial partners.

\section{Governance}

It is the inter-dependence between agreement components, as well as WATERS consortium members, that defines programmatic synergy allowing the optimization of resource utilization for consortium-wide capacity enhancement resulting in member-specific productivity maximization and cost minimization. In order to maximize synergistic utility, the activities of the WATERS are governed by a Board comprised of representatives from each member organization. The Board represents the interests of the respective member agencies by:

- Directing the consortium's strategic planning process;

- Evaluating the performance of the consortium;

- Maintaining primacy in authority delegated from the consortium member for all issues requiring supervisory control over resources (human, equipment, facilities) assigned to the WATERS.

- Ensuring that the financial, technical, and administrative commitments and expectations of the partnering agencies are met.

- Exercising approval authority over the appointment of the Executive Director and Operations Director.

- Exercising approval authority over the acceptability of delegated facilities and equipment.

Any organization joining the consortium has a right to appoint a representative to the governing board.

\section{Staffing}


Reporting to the governing Board, is an Executive Director, an Operations Director, and Unit Managers of each of the operating units. The CWRS Director and Associate Director serve as the Executive Director and the Operations Director respectively. The lab is currently divided in to two primary operating units - Chemistry and Biology. The Biology division is further subdivided into Microbiological, Cryptosporidium and DNA analytical units. Technicians and student trainees and interns are assigned within these operating units.

\section{Membership}

Under the original agreement, quantitative criteria were used to assign membership rights. This strict interpretation has relaxed as the consortium has grown. Two levels of membership were initially conceived for WATERS:

- Full Membership requires delegation of both personnel (professional/technical staff), and capital equipment to the continued operation of WATERS, and affords two representatives to the governing board, with oversight of all activities of WATERS.

- Affiliate Membership requires a demonstrated commitment to the vision of WATERS through the concomitant contribution of resources and utilization of WATERS services. Affiliate Members may nominate one representative to the Governing Board with oversight of activities specific to the Affiliate's role.

\section{Business Model}

Although housed within an academic division at WKU, from a business perspective, the WATERS laboratory functions as a service center, providing goods and services both to academic departments directly, as well as the general public at market rates.

Pricing Model - The primary benefits of membership is in the pricing structure for analytical services, along with the opportunity for training. The average discount for members is driven

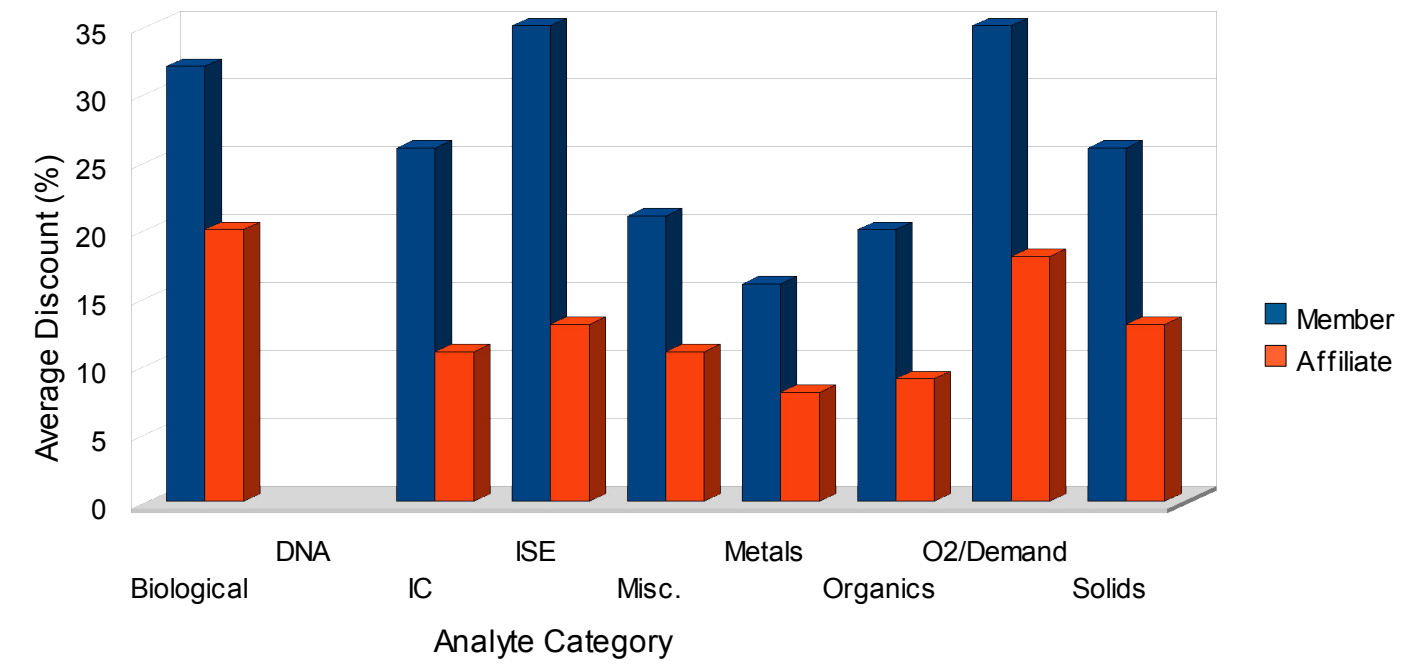

Illustration 1: Discount for Member Categories 


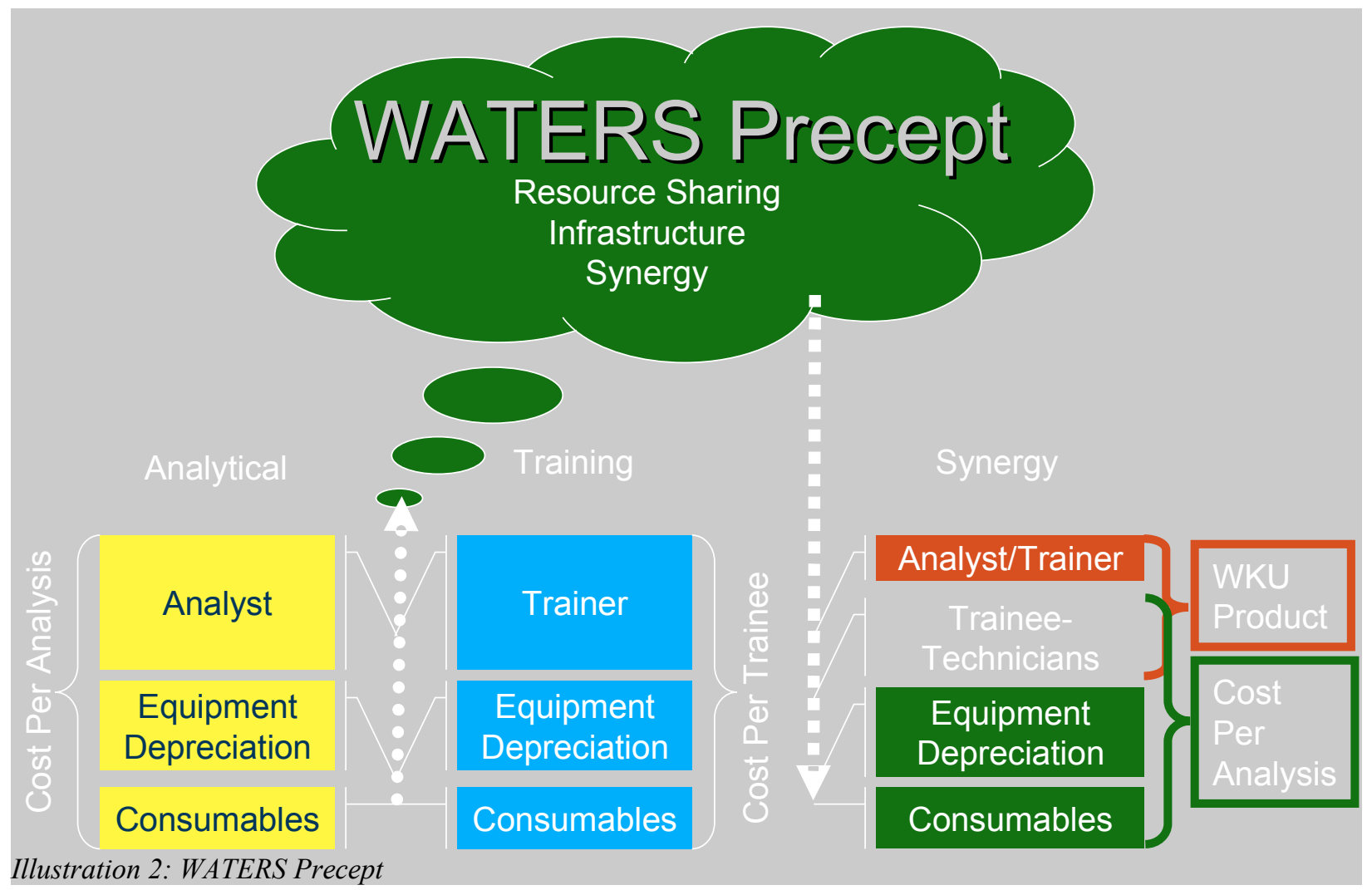

both by the level of contribution to the consortium, as well as a qualitative index of the market value of the analysis itself (Illustration 1). Pricing for analytical services was developed on a cost category basis. For each analyte, unit costs were determined based on labor, expendables, equipment life-cycle, and administrative overhead (Illustration 2). A similar approach was taken with the training services. A synergistic relationship in the training program allows some offsetting of trainer costs with the workload input of trainees.

Market Development - In keeping with the capacity development focus of the CWRS, WATERS has positioned itself in partnership with other commercial laboratories. Cognizant of being housed within a university structure, WATERS strives to ensure that its services are complementary rather than competitive with its peers. Advertising and promotion activities are muted, and limited to exhibits at trade shows, and are generally delivered within a membership recruitment or capacity development context.

Research Support - In addition to providing services to commercial clients, WATERS provides cost-based analytical support to other units within the university structure. Researchers will typically retain the services of WATERS in situations where relatively high volume of samples need to be processed, or when needing strict quality assurance/quality control structures or state certifications are needed. If the fund source is state or federal, an internal rate structure, that does not include university Facilities or Administrative (F\&A) costs, is used. This ensures that the target sponsor is billed for F\&A within the context of the university's negotiated rate, and allows the Principle Investigator to cost-share the discount if needed.

\section{Member Projects}


Mammoth Cave National Park - The WATERS lab provided analytical support for water quality parameters in support of the NPS Long Term Ecological Monitoring (LTEM) program and the Water Quality Monitoring Program for the Cumberland-Piedmont Network (CUPN) at Mammoth Cave National Park. The bulk of the analyses were conducted using instrumentation delegated from MACA to WATERS, affording a significant cost savings per analysis.

City of Bowling Green - After the initial establishment of the WATERS consortium with MACA and WKU as the founding members, the first municipality to join as a Affiliate was the City of Bowling Green. The City provided financial support for an intern, and continues to utilize WATERS for routine monitoring of stormwater management structures. This relationship has proven to be a valuable pre-employment vetting and recruitment process for entry-level staff within the Public Works department.

\section{Technology Development}

Cryptosporidium Monitoring Source Water Filtration - Under the Interim Enhanced Surface Water Treatment Rule[1] and final LT2 Rule[2], certain public water systems are required to monitor for the specific waterborne pathogens (e.g. Cryptosporidium and Giardia Lambdia). With the analytical methods requiring the filtration of 10L of source water under precise pressure and flow conditions prior to staining and microscopic enumeration, the WATERS laboratory devised product allowing the utility or municipality to filter the source water on-site and ship only the filter. Over a 2-year monitoring period, the estimated savings for the utility could approach $\$ 5,000$. Two models were developed, one requiring manual adjustment to meet pressure and flow requirements, and an electronically controlled version that automated the entire process. Units were provided to existing WATERS clients and used as a means to develop new clientèle.

Total Coliform Rule Expert System - In conjunction with the CWRS/EIIT, WATERS is developing rules-based decision support tools to enable small communities to rapidly adapt to monitoring requirements from USEPA and/or KDOW rule-making. The initial efforts resulted in a decision support tool[3] specific to the Total Coliform Rule[4].

\section{Capacity Development}

Back-Office/Exotic Analysis - As a university housed entity, WATERS has access to analytical capacity typically beyond the financial capacity of smaller laboratories. In keeping with its core capacity development mission, WATERS develops cooperative agreements will these labs in an effort to expand the scope of their services. Under these agreements, WATERS provides the "back-office" analysis at a pre-negotiated "wholesale" rate, while the partnering laboratory "retails" the services to their existing client-base. This synergistic relationship promotes the commercial growth and success of the partnering laboratory while allowing WATERS to evolve its analytical capacity as regulations change and the applied needs of involved WKU researchers change. A classic example of such a partnership is with Appalachian States Analytical, Inc. (ASA), in which the filtration device described above is provided as part of the commercial laboratories' suite of services. ASA is able to provide cryptosporidium analyses for its clients without having to invest in the costly equipment and certification requirements to do so. 
Shipping costs are minimized through the use of the filtration device, and WATERS is able to cash-flow some of its capital investment in the analytical infrastructure through the discounted analyses to ASA.

Small Systems Partnership for Compliance Monitoring - The small systems partnership for compliance monitoring was established primarily to assist the small utilities and municipalities meeting with the technical, financial burden of compliance monitoring. A variety of approaches have been implemented to achieve this, including leveraging technical assistance public fund sources and developing volume pricing structures for members of the partnership. Integrated into this strategy is the promotion of "Full Cost Pricing"[5] to ensure that the water systems are able to meet current and anticipated expenses for compliance monitoring.

\section{Workforce Development}

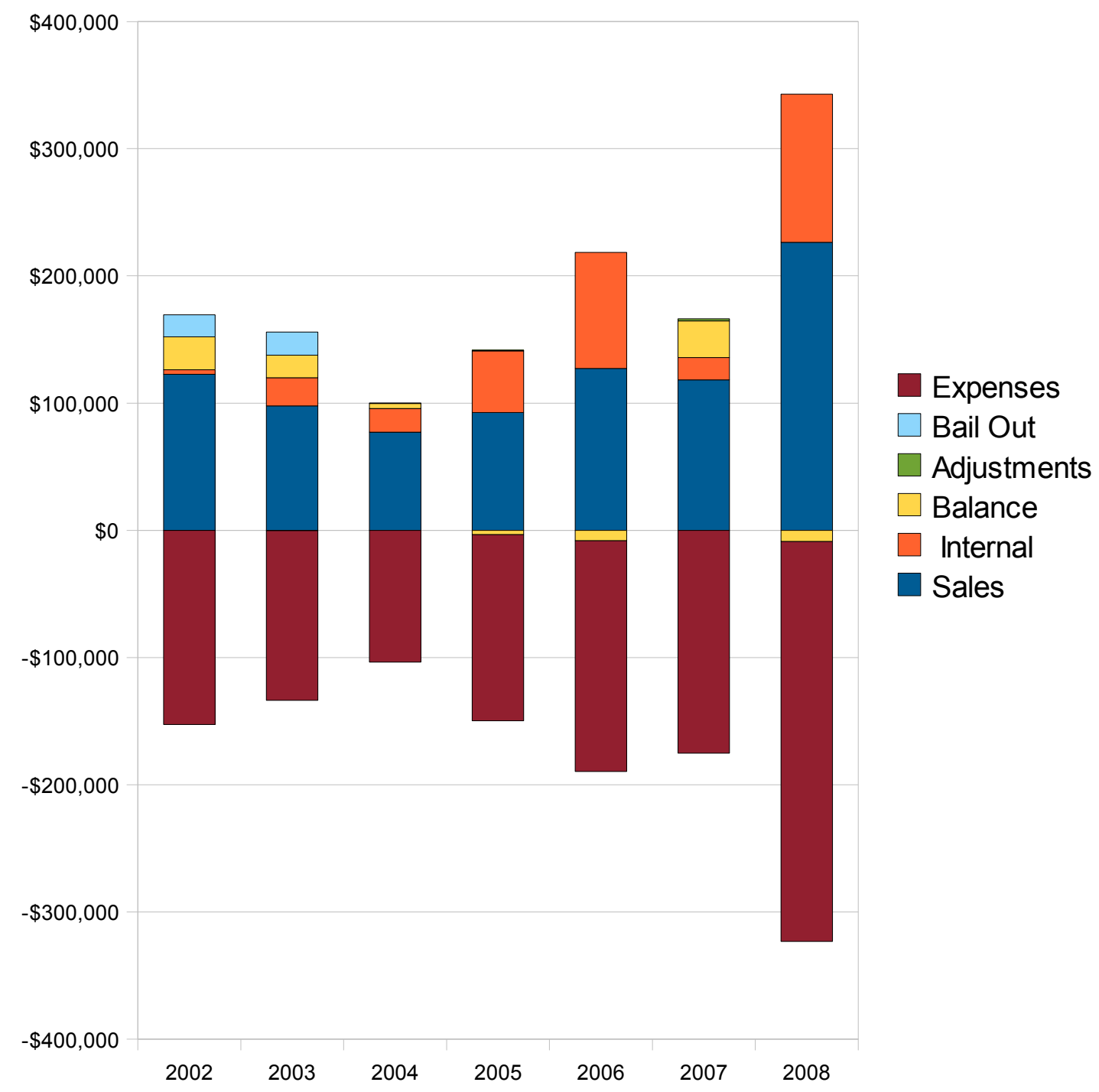

Illustration 3: Annual Cash Flow 
Outreach and Training - Each operating unit within WATERS is charged with engaging as many student workers as possible while still meeting certification standards. These students are provided training the appropriate analytical techniques and are provided support for securing relevant state or federal certifications under the guidance of core staff. In addition to training student interns and trainees, WATERS staff actively contribute to continuing education training programs hosted by partnering water and wastewater industry trade associations. For example, WATERS hosts workshops to train small water systems in the proper collection, preservation, and transportation techniques of drinking water samples. This helps ensure that few samples are rejected by any certified drinking water laboratory, including WATERS, the system may engage for their required periodic sampling. Training is also provided on emerging contaminants and other less frequent analytical requirements, such as those imposed by the LT2 Rule[2].

Water \& Wastewater Technician Training Institute - WTTI[6] is separate workforce development program for water and wastewater operators initiated by the CWRS in 2006. Program content is delivered primarily on-line, simultaneously both for CEU/certification and academic credit towards an associates degree in Water Utilities Management. Students are remote/rural areas are provided hands-on experiences by local partnering water and wastewater systems, will traditional students at WKU receive their experiential content through WATERS.

\section{Performance}

Illustration 3shows the financial performance of the laboratory from two years prior to reconstitution as WATERS to the last year. Cashflow values are calculated at fiscal year end (June 30). Approximately $\$ 35,000$ in university monies had to be injected ("Bail Out") into the OEL over FY '02 and and '03 to maintain solvency. In FY '07, after 3 years of sustained growth, WATERS underwent a self-evaluation and strategic planning process resulting in an internal organizational restructuring. Simultaneously, in anticipation of the impact of the LT2 Rule, WATERS made a significant investment in infrastructure, resulting in the dramatic growth experienced in FY '08.

\section{Educational Impact}

Over 20 students have been trained in the laboratory since 2004, of which 2 were hired as full time employees either of the WATERS Lab or the CWRS upon graduation. A qualitative assessment of workload indicates that over to half the effort expended by the lab is supportive of university-researcher sponsored projects. These projects include work related to disinfection byproducts, ammonia-oxidizing bacteria, source water quality assessments, total maximum daily loads, and karst environmental research work. In general, projects executed for university faculty include those in which the lab can afford to provide a nominal subsidy to support the start-up efforts of entry-level faculty, projects in which detailed, document-able quality assurance procedures are needed, and those that require exotic instrumentation available in the WATERS lab.

\section{Summary}

In five years of operation, WATERS has successfully balanced competing goals of research 
support, technology development, training, capacity development and financial solvency. In doing so, the organization has experienced dramatic evolution, both in terms of capacity and regional impact. Key to its success has been maintaining and expanding the diversity in the market sectors it serves. WATERS is currently in the midst of another details self-evaluation and strategic planning process.

\section{Bibliography}

1: Environmental Protection Agency, Interim Enhanced Surface Water Treatment Rule, 1998, Federal Register.

2: Environmental Protection Agency, Long Term 2 Surface Water Treatment Rule, 2006, Federal Register.

3: Suresh Jayanty, A Rule Based System Framework for Small Water Systems, 2005, Masters Thesis, Western Kentucky University.

4: Environmental Protection Agency, Drinking Water; National Primary Drinking Water Regulations; Total Coliforms, 1989, Federal Register.

5: Environmental Protection Agency, Expert Workshop on Full Cost Pricing of Water and Wastewater Service, 2006, Michigan State University.

6: Andrew N.S. Ernest, Jana R. Fattic and Sherry Reid, An Integrated Systemic Approach to Developing a Professional Water and Wastewater Workforce, 2008, Conference Proceedings, American Society for Engineering Education. 